\title{
A expansão do ensino primário rural na região de Birigui - Noroeste Paulista - Brasil (1920-1960)
}

\section{The expansion of rural primary education in the region of Birigui - Noroeste Paulista - Brazil (1920-1960)}

\author{
Áurea Esteves Serra \\ Fundação Municipal de Ensino. Faculdade de Ciências e Tecnologia de Birigui, \\ Birigui/SP. Brasil, prof.aureafateb@gmail.com
}

\section{Resumo}

Este estudo compreende a atividade educativa formal desenvolvida pelo governos municipal e estadual na zona rural do município de Birigui/SP, entre 1920 a 1960, levando em consideração os antecedentes de colonização e imigração. O objetivo consiste em apontar algumas notas sobre o desenvolvimento da escola primária rural no município de Birigui/SP, por meio da localização, reunião e analise de fontes documentais. Para a analise desse objeto de estudo, procedeu-se à utilização tanto de indicadores do tipo quantitativo, como qualitativos. O ensino primário rural no Brasil segundo Ávila e Souza (2013) na década de 1940 foi concebido para instruir, civilizar, moralizar, higienizar e nacionalizar, tendo por objetivo fixar o homem no campo para segurança nacional, daí o expressivo número de escolas rurais, inclusive em Birigui/SP.

Palavras-chave: Imigração. Colonização. Escolas rurais. Noroeste Paulista. Brasil.

\section{Abstract}

This study comprises the formal educational activity developed by the municipal and state governments in the rural area of the municipality of Birigui / SP, between 1920 and 1960, taking into account the antecedents of colonization and immigration. The objective is to point out some notes about the development of rural primary school in the municipality of Birigui / SP, by locating, meeting and analyzing documentary sources. For the analysis of this object of study, both quantitative and qualitative indicators were used. Rural primary education in Brazil according to Avila and Souza (2013) in the 1940s was designed to educate, civilize, moralize, sanitize and nationalize, with the aim of establishing man in the field for national security, hence the expressive number of rural schools, including in Birigui / SP.

Keywords: Immigration. Colonization. Rural schools. Northwest Paulista. Brazil. 


\section{Introdução: colonização e imigração em Birigui/SP}

Como esta pesquisa trata de uma localidade específica - a cidade de Birigui/SP -, faz-se necessário lembrar que essa cidade surgiu em decorrência da construção da Estrada de Ferro Noroeste do Brasil ${ }^{1}$ e a instalação da Companhia de Terras, Madeiras e Colonização do Estado de São Paulo², ambas, estratégias de colonização.

A cidade de Birigui cresce rapidamente em decorrência da expansão da cultura de café para o oeste paulista, particularmente, região Noroeste. No primeiro momento, era somente uma Chave, onde o trem parava três vezes na semana, sendo o povoado fundado, em 7 de dezembro de 1911, por Nicolau da Silva Nunes.

A ocupação territorial espacial da região foi feita pela Companhia... ${ }^{3}$, que tinha como objetivo adquirir terras nas proximidades da estrada de ferro, que serviriam para o fluxo de escoamento, tanto de produtos agrícolas, como de passageiros, o que facilitava o loteamento e a venda da terra para os novos colonos. Para atrair os compradores de terras em Birigui, a Companhia anunciava nos principais jornais da cidade de São Paulo e do interior do estado e também nos jornais das colônias dos imigrantes italianos, espanhóis, alemães e japoneses. Assim nasce Birigui, uma cidade administrada por inglês e escocês e colonizada por muitos imigrantes, em sua maioria italianos, japoneses, espanhóis e portugueses.

Com relação ao desenvolvimento da temática, utiliza-se a matriz interpretativa cunhada por Rémond (2003), sobre a história política, e também por Norbert Elias (1997), sobre civilização. Para esse último autor, civilização e violência são temas constantes e atuais para a compreensão do movimento na história. Para Elias (1997) o poder é uma característica de todas as relações humanas e está ligado ao grau de dependência entre os indivíduos, seja pela força, seja pela necessidade econômica, seja pela de cura, seja pela status, seja pela carreira ou seja por excitação. É em contexto semelhante a esse descrito por Elias (1997) que começa a nascer a cidade de Birigui, uma cidade projetada e de certa forma controlada pelos seus colonizadores.

O processo de colonização e povoamento de Birigui foi marcado pela disputa da terra primeiramente entre os índios e a empresa de colonização Companhia... e, na sequência, entre os fazendeiros latifundiários e os posseiros. Cabe esclarecer que o "poder" político econômico exercido na região se constituiu com os membros da Companhia... Com isso, infere-se que se não fosse a influência política dessa empresa, o processo de colonização de Birigui não teria conseguido chegar aonde chegou. Para muitos autores esse foi o fato da cidade se desenvolver muito rápido nos seus primeiros 20 anos, algo positivo, mas quando visto do sentido da política local, algo negativo, porque o poder ficou centralizado na mão de um grupo por mais de 30 anos. Há registros em jornais da época que alguns políticos e pequenos agricultores, por vezes, não concordavam como o monopólio exercido pela Companhia...

Em decorrência da colonização, foram realizadas várias campanhas de incentivo a venda dos lotes de terra pela companhia... Com isso, chegam à região imigrantes de todas as partes do país e, principalmente, da Europa.

De acordo com Moreira (2008, p. 64) citado por Serra (2014a, pp. 292-293) "[...] entre 1880 e 1900, desembarcaram no Brasil 1.129.000 europeus - dos quais, 680.000 eram italianos". Esse número de imigrantes que chegam a Birigui em sua 
maioria eram de procedência italiana. Pisani (1937), ao tratar da colônia italiana em Birigui, afirma que: "La collettivitá italiana residente in questo Municipio si caleola composta di circa 4.000 persone; i figli d'italiani si fanno ascendere a circa 8.500 dedicano all' agricultura, in picolo numero alle industrie, al commercio e al mestieri" (pp. 521-522).

Ainda segundo esta autora, são principalmente esses italianos que vão cuidar da produção de café em suas pequenas propriedades nos bairros rurais, ou vão trabalhar como arrendatários ou meeiros. Conforme aponta Pisani (1937), são 492 os nomes de famílias italianos residentes em Birigui. Mas quando se confronta esta informação com a Relação dos Contribuintes do Imposto Cafeeiro, publicada em 1928, por Ercilla e Pinheiro, encontram-se muitos outros nomes de italianos que vieram para Birigui, os quais seus descendentes permanecem na cidade até hoje, 2014.

Ainda com base na obra de Serra (2014a), observa-se que a cultura do café expandiu em Birigui nas três primeiras décadas do século $X X$, para onde mudaram imigrantes italianos, a princípio instalados na região de Ribeirão Preto, e, em seguida, em Birigui. Na corrida para esse surto agrícola, investiu-se muito dinheiro nos estabelecimentos e máquinas de café dessa localidade, de modo que a maioria das sociedades instaladas eram anônimas. Muitas foram às máquinas instaladas para beneficiar o café produzido em Birigui. Esse dado confirma-se, porque a Zona Noroeste no ano de 1927 plantou cerca de 100 milhões de pé de café e muito algodão. Porém, o café imperou na primeira terça parte do século XX. Segundo Freitas (1999), foi a partir de 1881 que começou a ocorrer o "[...] aumento na produção de café no Oeste Paulista." (p. 78).

De certa forma, a estabilização da monocultura cafeeira em Birigui e o fantasmagórico surto de enriquecimento produzido pelo café contribuíram para o desenvolvimento muito rápido da cidade. Milhares de homens migraram à cidade com a esperança de um enriquecimento rápido e fácil. Com isso, a maior parte desses homens não retornou às suas origens, formando, assim, a cidade de Birigui.

Nota-se que a evidência dessa imigração e migração pode ser constatada nas estatísticas de $1929^{4}$, quando Birigui contava com 30 mil habitantes, dos quais somente 4.500 estavam na cidade, zona urbana, e os outros 25.500 estavam na zona rural. Assim, a economia biriguiense foi essencialmente agrária nesse período; a população de origem principalmente européia estava em sua maioria instalada na zona rural, no trabalho com a terra.

Faz-se necessário dizer que Birigui, desde seus primórdios, contava com energia elétrica, telégrafo, tudo isso em virtude da instalação da Companhia Estrada de Ferro Noroeste do Brasil e da Companhia... nessa cidade. Birigui ainda contava com três paradas do trem para o escoamento de sua produção: Coroados, Birigui e Guatambu. Para Rémond (2003):

O desenvolvimento das políticas públicas sugeriu que a relação entre economia e política não era de mão única: se não há dúvida de que a pressão dos interesses organizados às vezes altera a condução dos negócios públicos, a recíproca não é menos verdadeira: a decisão política pode modificar o curso da economia para melhor ou para pior. (Rémond, 2003, p. 23). 
Cabe destacar que no ano de 1929 o município de Birigui contava com 25.000.000 pés de café, sendo 900 as grandes propriedades cafeeiras e 3.000 o número de sitiantes. Mas a grande marca aferida pela morte da economia cafeeira birigüiense se deu primeiramente pelo fato apontado por Freitas (1999), o colapso do café em 1928, no qual os grandes estoques, a lavoura endividada e a queda acentuada nas exportações contribuíram para a queda da Bolsa de Nova lorque no ano de 1929. Segundo Freitas (1999), uma "quebradeira geral" (p. 78), quando milhares de sacas de café foram queimadas em todo o país, não sendo diferente em Birigui.

De acordo com Serra (2014b) a crise por que passou nosso país com esse fato e, particularmente a cidade de Birigui, deixara-lhe profundas marcas até esse mal nacional arrebentar com a Revolução de $1930^{5}$. Porém, em Birigui, mesmo o município participando diretamente da revolução, enviando vários combatentes, suas atividades continuaram a crescer. Ainda conforme Serra (2014a), de acordo com as informações publicadas na revista Os Municípios (1939), Birigui contava com uma população de 54.500 habitantes em 1939, sendo que destes 39.800 estavam na zona rural e os demais nos distritos e município. Existiam no município em 1939, 20.221.763 cafeeiros em produção e, das 2.089 propriedades agrícolas, 1.191 eram de lavouras cafeeiras, tendo Birigui exportado nos anos de 1937 - 318.153 sacas de café, no ano de 1938 - 402.069 e, no ano de 1939, 188.338 sacas.

Os agricultores foram imprescindíveis para a economia da cidade de Birigui, gerando seu desenvolvimento. Vinham da Europa alfabetizados, portanto uma preocupação destes, era reivindicar escolas para seus filhos. Com isso, dá-se inicio a criação de escolas rurais e urbanas no município.

\section{A expansão do ensino primário rural na região de Birigui/SP}

Para Serra (2011), a organização escolar na zona rural de Birigui se fez necessária porque a maioria da população residia no campo. Assim foram muitas as escolas criadas no município. "Escolas de ordem particular nas fazendas e outras criadas pelo município e pelo governo estadual” (p. 52).

Segundo Serra (2007), o ensino na cidade de Birigui aconteceu de acordo com a ênfase que se deu à expansão da escolarização no Brasil em torno das décadas de 1920 e 1930, como o movimento escolanovista, no qual a partir da década de 1950 se iniciou no Brasil um processo desenvolvimentista que explica, em particular no Estado de São Paulo, a expansão dos grupos escolares, das escolas isoladas, dos ginásios, dos colégios e dos institutos de educação pela capital, litoral e interior, o mesmo aconteceu na cidade de Birigui com a criação de várias escolas e de um instituto de educação

Ainda segundo Serra (2007), a cidade de Birigui chegou a ter nas décadas de 1950, 1960 e 1970 mais de 40 escolas rurais entre comum isoladas e de emergência.

Com isso, confirma-se que o ensino em Birigui, assim como nas demais cidades da região Noroeste, foi municipal e primário até a criação das escolas reunidas, dos grupos escolares e escolas isoladas pelo governo estadual. 
Civera (2011), tratando sobre a educação do campo na América Latina, aponta que muitas vezes para podermos localizar a escola devemos levar em conta que:

\begin{abstract}
Podemos ubicar la escuela en su entorno tanto local como nacional y global en una relación de complicidad, competencia o conflictividade con otras instituciones culturales, sociales o económicas, o pensar la escuela como processo: como resultado de la acción de diversos sujetos y a la vez como estructura que marca los limites de su acción, en una organización específica del tiempo y del espcio que se construye en sus rutinas y ritos diarios. (p. 9)
\end{abstract}

É nesse sentido que passo a discorrer sobre a legislação que normatizou a escola pública primária rural municipal.

De acordo com Ávila (2013), "[...] até 1917 não havia no estado paulista uma classificação quanto à localização das escolas isoladas." (p. 69). Somente com Oscar Thompsom, a partir da publicação da Lei no. 1.579, de 19 de dezembro de 1917, regulamentada pelo Decreto №. 2.944, de 08 de agosto de 1918, foi que as escolas isoladas passaram a ser classificadas em "ruraes, districtaes" e urbanas. Ávila (2013) afirma que a instrução pública paulista foi marcada por constantes reformas ao longo dos anos de 1920 e, dentre essas reformas, destaca a de Sampaio Dória com a Lei ㄲo. 1.750, de 08 de dezembro de 1920, regulamentada pelo Decreto no. 3.356, de 31 de março de 1921, que vai tratar do papel central das escolas isoladas rurais na campanha de alfabetização. Para Ávila (2013), esse era um problema de urgência em virtude da organização do aparelho escolar amparado pelas correntes renovadoras do pensamento moderno, nas quais os governantes e reformadores se depararam com um cenário rural muito desfavorável: escolas precárias e insuficientes, instabilidade de professores, elevados índices de analfabetismo e, ainda a chegada de inúmeros imigrantes no estado.

Em Birigui, segundo Ercilla e Pinheiro (1928), a educação local começa a 'ser organizada em 1912, quando foi instalada a primeira escola para os filhos das pessoas que vieram morar em Birigui, organizada por pessoas que sabiam ler e escrever. Com isso, "[...] reuniram-se as crianças da povoação; meninos e meninas para dar-lhes algumas instruções" (p. 492).

Com o Código de Educação de $1933^{7}$, a escola pública primária rural passou a ser denominada de escola isolada e, no artigo 253 da referida lei, aparece o termo escolas isoladas rurais. $O$ artigo 257 também dessa lei trata da instalação das escolas isoladas determinando que: "[...] para o provimento de escolas da zona rural, será dada preferência àquelas em que a municipalidade ou os particulares interessados tomem para si, o encargo da instalação, comprometendo-se: a) a doar ao estado terreno e prédio nas condições especificadas no artigo 256." (São Paulo, 1933, p.71).

Em Birigui, presume-se que este artigo foi cumprido, porque nessa região foram instaladas várias escolas isoladas, às quais eram de interesse de particulares, como inúmeros fazendeiros que doaram terrenos e prédios para o funcionamento destas.

O Código de Educação de 1933 em seu artigo 253 diz que: "[...] para instalação de escolas isoladas indispensável à existência de pelo menos quarenta (40) crianças em condições de matrícula, dentro de uma área de dois quilômetros de 
raio" (São Paulo, 1933, p.71). Assim parece ter acontecido em Birigui. Recordo que durante o desenvolvimento da pesquisa que resultou neste texto, analisando mapas de movimento na Diretoria de Ensino, chamou-me a atenção o fato de várias escolas terem 40 crianças matriculadas. Isso despertou certa curiosidade, que levou-me a pensar: era real os dados ou eram maquiados para se atender a essa legislação.

De acordo com o Annuario do ensino do Estado de São Paulo de $1937^{8}$, no de ano 1936 no estado de São Paulo o número de escolas isoladas rurais era de 3.356 e o número de matrículas de 101.624 alunos entre 8 e 11 anos.

Em Birigui, registra-se que no ano de 1946 as matrículas efetuadas em uma classe feminina de $1^{\circ}$ ano ficava em torno de 7 a 13 anos de idade e, no ano de 1963, de 5 a 12 anos. Em entrevista com ex-professora do município, essa afirma que:

[...] quando eu penso naqueles meus aluninhos, lá de Juritis, eu tinha 52 alunos você sabe o que é Juritis? Que os pais colocaram na carteira e foram para a roça eu fico pensando quanto medo essas crianças sentiram! [...] (p.139-140).

[...] eu tive crianças de cinco anos que aprenderam a ler e escrever. Como eu tive crianças de 12 anos que não aprenderam (Bigélli, 2011, p. 143).

Vale assinalar que a escola primária rural nas décadas de 1930 e 1940 teve um papel importante na modernização do país e na construção da nacionalidade. No país e em Birigui, essa expansão do ensino primário rural ocorreu por meio da criação de escolas e, consequentemente, a ampliação do número de matriculas tem início nos anos de 1920. Nacionalmente, o objetivo era fixar o homem no campo, trabalhando com noções de técnicas agrícolas, educação sanitária, como noções de higiene e o combate de doenças, tudo isso tendo por objetivo levar a modernização à zona rural.

Minicucci (1948) mencionou em seu artigo "1ํㅡㄹ Congresso rural de Birigui: escolas para a zona rural" quais as medidas que deveriam ser postas em execução para que toda criança da zona rural do estado de são Paulo recebesse os benefícios da instrução primária. O referido autor assim discorre:

1 - Proceder-se a um planejamento para distribuição de escolas, mediante um estudo meticuloso da concentração demográfica, atividades reinantes, condições de estabilidade do professor.

2 - Diminuir-se o número de crianças exigidos para a instalação de escolas, pois atualmente o Estado só as localiza onde há mais de 40 menores em idade escolar. Desse modo, os pequenos núcleos onde estão é possível atingir esse limite se vêm privados de instrução primária. Somem-se esses conglomerados e teremos uma cifra alarmante de crianças que não freqüentam escolas primárias.

3 - Deixar a cargo das Prefeituras Municipais a instalação de escolas primárias em núcleos com 15 crianças no mínimo. O Estado criaria escolas em lugares onde houvesse, por exemplo, mais de 30 crianças. Assim, toda a zona rural seria beneficiada e favorecer-se-ia a pequena propriedade, que é a maior fonte de produção e riqueza.

4 - Serem fazendeiros responsáveis pelos menores em idade escolar, que deixam de freqüentar as escolas existentes. É muito comum o lavrador utilizar-se do serviço do menor em detrimento da frequencia às aulas, com tácito consentimento do fazendeiro. 
5 - Preparar, convenientemente, o professor, para a zona rural, pois é raro aquele que sente inclinação para a vida do campo, fazendo deste apenas um estágio da sua carreira. Isso se reflete no animo da criança, que sente, desde cedo, intensa atração pela cidade.

6 - Proceder-se a um estudo urgente para e estabelecimento dos períodos letivos nas diversas regiões do Estado. Em nossa zona, por exemplo, os contratos agrícolas terminam em setembro ou outubro, meses em que as escolas se despovoam. Os alunos que se retiram de uma escola não encontram mais lugares nas outras, uma vez que as matrículas estão encerradas e o ano letivo quase findo. Diante disso, essas crianças têm um período reduzido de estudo, intercalado por umas férias forçadas muito longas, que influem no aprendizado (pp. 71-72).

Minicucci (1948) termina o artigo afirmando que essas foram as suas considerações na intenção de contribuir para a solução dos preementes problemas da educação no campo em Birigui e no estado de São Paulo. Todavia, necessário se faz ressaltar que, embora muitos estivessem preocupados com a educação rural, os problemas persistiam, dentre eles, o analfabetismo. em muitos estudos se observa que o panorama nacional do analfabetismo ao longo do processo de escolarização expressa, até a década de 1950, um percentual de mais de $50 \%$ de indivíduos analfabetos, embora o governo tivesse criado vários programas. Dessa forma, constata-se que a política de escolarização caminhou a passos lentos em nosso país. Isso possibilita confirmar o fato por demais conhecido de que as diferenças econômicas, sociais e culturais se refletem em desigualdades de acesso e integração escolar. Para Pereira (2013), "[...] una de las grandes causas de la insuficiencia de oportunidades de escolarización la dispersión de la población rural" (p. 183).

Carramaschi (1948) também escreveu no seu artigo "O problema do ensino primário na zona rural" que, em toda a região que abrangia a Delegacia de Ensino de Araçatuba, somente conhecia um professor que optou por permanecer no campo. Também escreveu 13 itens que segundo seus estudos seria necessário para resolver o problema das escolas rurais. São eles:

1 - Maior entusiasmo do professor, para integrar-se ele na vida do povoado ou bairro onde se encontra a sua escola.

2 - Maior interesse, por parte dos fazendeiros, às coisas do ensino.

3 - Saneamento rural, para elevação do nível econômico do núcleo.

4 - Condições especiais dos trabalhos agrícolas.

5 - Estabilidade de professores e alunos.

6 - Aparelhamento didático apropriado.

7 - Assistência ao professor.

8 - Assistência aos alunos por parte das Caixas Econômicas.

9 - Assistência médico-sanitária, por parte dos Centros de Saúde.

10 - Proibição do trabalho de menores de 14 anos, durante o período escolar.

11 - Área cultivável para a feitura de hortas e jardins.

12 - Ano escolar correspondente ao ano agrícola.

13 - Organização de um programa afeito a zona rural, adaptável as situações do meio (p. 95). 
Carramaschi (1948) termina essa parte da exposição escrevendo: "Se em nosso município conseguirmos fixar o professor ao local de sua escola, dando-lhe remuneração e estabilidade condigna, posso afiançar que o problema do ensino primário na zona rural, será um ponto solucionado" (p. 95). Após essas reflexões, Carramaschi (1948) continua seu texto discorrendo sobre o professor Lauro Bittencourt, que aportou de longínquas terras para fazer estágio e, "[...] encontrando ambiente bastante favorável, até hoje ali se encontra, integrandos-e na vida do bairro, tornando-se mesmo proprietário agrícola" (p. 95).

Carramaschi (1948) teceu uma critica dizendo que o problema do ensino primário no campo era debatido nos congressos porém não passava de palavreados, uma vez que somente aconteceu uma melhora com Sud Menucci, em 1932, "[...] num esforço titânico tentou organizar o ensino rural, tendo sido o mesmo regulamentado pelo governo de então" (p. 94), General Manuel Rabelo e Pedro de Toledo. Continua Carramaschi (1948) discorrendo que o "posterior governo revogou o decreto e os problemas continuaram" (p. 94). Carramaschi (1948, p. 94) afirma: "desde 1943, venho realisando, nas escolas campesinas, os exames finais. Baixíssimas tem sido a porcentagem de promoção, quase nula a sua freqüência [...]".

De açodo com os estudos realizados constatei que a criação das escolas isoladas rurais de Birigui, mantidas pelo poder público municipal e estadual, estavam relacionadas em grande parte ao grau de desenvolvimento econômico do bairro onde se acham instaladas e ao número da população ali residente. Segundo Serra (2011), os bairros do Tupi e Moinho chegaram a ter de três a quatro escolas em virtude da população ali residente.

De acordo com as informações disponibilizadas na revista Birigui em sua 1a concentração rural, no ano de 1948 essa cidade tinha-se 22 escolas isoladas estaduais rurais e 12 escolas isoladas municipais, sendo seis urbanas e seis municipais. Quanto aos grupos escolares, havia quatro, sendo dois na zona urbana e dois na zona rural. Os da zona rural foram criados pelo Decreto de 3 de setembro de 1946 e instalados no dia 13 do mesmo mês e ano. O Grupo Escolar rural do Bairro Taquari no ano de 1948 possuía quatro salas de aula, com um total de 160 alunos. O Grupo Escolar rural do bairro Baguassú também continha com quatro salas e um total de 147 alunos. Segundo Souza (1998), grupos escolares era onde se reuniam várias classes, com alunos divididos em turmas e cada classe sob a regência de um professor. Essa organização era feita no mesmo estabelecimento.

Outra constatação que vai ao encontro do que é apontado nacionalmente é a evasão e a repetência. De acordo com Almeida (1945), de cada 100 alunos de escolas isoladas rurais, somente 40 chegavam até o fim do $2^{\circ}$ ano. Almeida (1945) aponta que o percentual de reprovações ficava em torno de $40 \%$. É alarmante 0 número de reprovação ou evasão registrado nos Mapas de Movimento das Escolas Isoladas Estaduais de Birigui, de 1938 a 1955.

Analisando os dados que constam nos Mapas de Movimento das Escolas Isoladas Estaduais de Birigui, de 1938 a 1955, quanto aos alunos eliminados (evadidos), nota-se que a evasão nas escolas isoladas rurais municipais ficava em torno de $26,83 \%$ para o sexo masculino e de $27,90 \%$ para o sexo feminino. A partir desta constatação, cabe assinalar que no interior das escolas as diferenças sociais, culturais e econômicas se traduzem em desigualdades de acesso, integração e sucesso escolar dos alunos, apresentando-se no interior das escolas muitas vezes 
em estratégias de rotulação, discriminação e situações de desvantagem, que costumam responder ao abandono da escola.

Perante toda essa situação, sabe-se que a escola rural brasileira no princípio do século XX era muito incipiente, tanto no aspecto quantitativo, como no qualitativo. Com isso, na década de 1920, nota-se em Birigui um desajuste entre o número de alunos e o número de escolas oferecidas. Há necessidade da sociedade era que a instalação do sistema educativo fosse capaz de atender a todos, um sistema educativo mais abrangente. Percebe-se que a educação não se expande no ritmo que exige a explosão demográfica, somente no período dos anos de 1930 é que a expansão do ensino primário rural começa a ocorrer devido à política intervencionista do governo, pois se sabe que Getúlio Vargas foi presidente do Brasil em dois períodos, sendo o primeiro por 15 anos ininterruptos, de 1930 a $1945^{9}$. No segundo período, em que foi eleito por voto direto, Getúlio governou o Brasil como Presidente da República, por três anos e meio: de 31 de janeiro de 1951 até 24 de agosto de 1954. De acordo com Serra (2014b), foi nesse período que ocorreu a grande expansão do ensino primário rural em Birigui. Para Souza (2013), dois aspectos marcam a história do ensino primário no estado de São Paulo no século XX, entre as décadas de 1930 e 1960: "a expansão continua e acelerada das oportunidades educacionais alicerçada na diferenciação espacial e interna da rede escolar e a renovação pedagógica instituída pelo Estado com base nos princípios da Escola Nova" (p.1).

De acordo com Serra (2014b), a edição do jornal $O$ Biriguyense de 30/10/1938 noticia que Birigui contava com 8.500 habitantes na sede do município; 3.200 habitantes nos distritos; e 37.500 na zona rural, perfazendo assim um total de 49.200 habitantes. Ora, se compararmos com o número de escolas na sede do município, podemos concluir que a zona rural detinha o maior número de escolas, uma vez que a população estava no campo.

De acordo com Serra (2007), Birigui no ano de 1940 tinha seis escolas urbanas e 21 escolas rurais e, no ano de 1957, nove escolas urbanas e 48 escolas rurais. Concluiu-se, de acordo com Serra (2014b), que o período educacional na Era Vargas, mesmo com a II Guerra Mundial, em Birigui, foi significativo para o posterior desenvolvimento desta área.

Buscando compreender todo esse processo de expansão da escola rural em Birigui e a imigração, se apresentam alguns quadros, que sintetizam algumas informações sobre a questão aqui discutida.

De acordo com os dados censitários do Instituto Brasileira de Geografia e Estatística [IBGE] (1950), se observa que a maior parte da população de Birigui até a década de 1950 encontrava-se no campo. Outro dado importante que deve ser ressaltado é que o aumento considerável da população de 1920 para 1930, pode ser atribuído a imigração.

Retomando a questão da implantação das escolas rurais de ensino primário em Birigui, constata-se que a primeira iniciativa foi municipal, porém, na década de 1930 o governo estadual também assumiu esse tipo de ensino como se confirma no quadro abaixo. Para Souza (2013), o Poder Público estadual foi "[...] responsável pela manutenção do maior número de escolas e matrículas e pela difusão do ensino." (p.1). Podemos confirmar essa informação com os dados extraídos de livros de matrículas e mapas de movimento das escolas rurais de Birigui/SP. A análise dos dados desses livros permitem refletir sobre algumas constatações decorrentes dos estudos realizados. Muitas vezes a "escola" era somente uma classe criada pelo 
governo municipal. Em um mesmo prédio se tinha classes criadas pelo governo estadual e pelo governo municipal. No entanto, cabe assinalar que as designações encontradas nos documentos curriculares analisados foram mantidas. De certa forma, foi essa fusão entre as iniciativas municipais e estaduais que contribuíram para a expansão das escolas rurais.

Para Ávila e Souza (2013a), estas afirmam que:

Entre as décadas de 1930 e 1960, o ensino primário rural emergiu como uma das problemáticas fundamentais da educação brasileira, passando a ocupar um lugar de destaque nos discursos de políticos, educadores e administradores do ensino público do país. (p.1).

Estas autoras ainda afirmam que:

[...] o expressivo aumento no número de escolas rurais na década de 1940, não se construiu no Brasil uma ideia uniforme em relação a essa modalidade de ensino. Ora a escola rural foi concebida para instruir, civilizar, moralizar, higienizar, e nacionalizar, ora como instrumento de modernização e fixação do homem ao campo e, ainda, como elemento de estabilidade e de segurança nacional. (Ávila \& Souza, 2013a, p. 25).

Neste sentido, quando se observa o número de escolas, constata-se que grande parte delas estavam na zona rural, onde está a grande maioria da população.

Para Minicucci (1948):

\begin{abstract}
As estatísticas demonstram que mais da metade de nossa população mora na zona rural. No entanto, esta conta com um número reduzidíssimo de escolas em comparação com os centros urbanos. Para comprovar esta assertiva, não precisamos ir muito longe. Comentemos com o nosso município: Birigui conta, aproximadamente, com 45.000 habitantes, dos quais 14.000 moram na cidade e 31.000 no campo. Há, na cidade, 1.740 alunos matriculados nos grupos escolares, escolas municipais e particulares e, 1345 alunos nos grupos e escolas rurais. Por aí podemos ver que a cidade apresenta a média de 304 habitantes para cada unidade escolar e a zona rural 837 habitantes para cada unidade. A desproporção é flagrante. Note-se ainda que Birigui é um município bem favorecido de escolas, em comparação com os demais da zona noroeste (p. 36).
\end{abstract}

Sobre esse aspecto, cabe ressaltar a necessidade de se ter mais escolas nos bairros rurais. Segundo Barros (2004) e Bezerra (2011) citados por Ávila e Souza (2013b), da diferenciação espacial das escolas isoladas a partir do pressuposto apontado pelos referidos autores, que atribuem à palavra bairro "[...] uma porção de território nas proximidades de um núcleo urbano" (Ávila e Souza, 2013b, p. 5) concluem a partir da documentação examinada que o uso do termo escola de bairro refere-se "[...] a localização da escola em povoados localizados nos arrabaldes da cidade ou aquelas situadas em zonas consideradas propriamente agrárias ou rurais" (p. 5).

No caso de Birigui, é nos bairros ${ }^{10}$ rurais que temos a grande maioria das escolas de ensino primário ${ }^{11}$. 
Referente à criação e fechamento das escolas rurais da região de Birigui, no caso aqui somente quanto as escolas municipais, foram localizadas quatro leis que tratam deste assunto e uma citação em um jornal de circulação diária dos anos de 1930.

Nesse estudo, a título de amostragem a partir dessas formulações e também em virtude da fonte documental localizada, apresenta-se o número de matriculada de 20 escolas municipais isoladas de Birigui entre os anos de 1931 e 1936 constatando que ocorre um aumento significativo de 1934 a 1936, e que essa média mantém-se até o ano de 1958. Trata-se apenas do período em questão, visto que foram localizadas somente duas fontes documentais, Mapas de Movimento, desses respectivos anos.

Também quanto às escolas isoladas estaduais, foram localizadas somente duas fontes documentais, Mapas de Movimento, referentes à década de 1940 e 1950. Observa-se ainda, que nos primeiros anos da década de 1940 o número de alunos matriculados nas escolas isoladas estaduais de ensino primário e a partir de 1945 ocorre um decréscimo, voltando a aumentar a partir dos anos de 1951.

Por outro lado, quanto à pesquisa, é interessante registrar que os livros de matrícula localizados são somente a partir do ano de $1946^{12}$. Este fato pode ser atribuído a criação da Delegacia de Ensino de Araçatuba somente no ano de 1947, de acordo com o Decreto no. 17.698, de 26 de novembro de 1947. Vale lembrar que anteriormente a região de Birigui pertencia a Delegacia de Ensino da cidade de Lins, depois Araçatuba e somente com o Decreto 7.510, de 29/01/1976, foi criada a Delegacia de Ensino de Birigui.

Entretanto, em um Mapa de Movimento, localizado na Diretoria de Ensino de Birigui, referente ao Grupo Escolar Rural do Taquari, no período compreendido entre 1946 e 1969, em relação ao número de matriculas, como apontado por Souza e Ávila, é no final dos anos de 1940 que começa a expansão de matrículas nas escolas rurais, continuamente até o final da década de 1950.

É interessante é observar que mesmo após quase três décadas da chegada do grande número de imigrantes italianos, ainda registra-se a presença de pais de alunas vindos da Itália e também de japoneses, sendo que o grande fluxo imigratório se deu na década de 1920 para os italianos e de japoneses na década de 1930.

Após a tabulação dos dados referente à matrícula no $1^{\circ}$ ano do ensino primário, classe feminina, do Grupo Escolar Rural do Taquari, temos: no ano de 1946, 46 matrículas; no ano de 1947, 35 matrículas 35; no ano de 1948, 19 matrículas, e no ano de 1948, 18 matrículas. Observa-se uma redução no número de matrículas, mas vale lembrar que se trata de uma classe feminina e que nesse período já havia as classes mistas.

Desse modo, pode-se afirmar que a imigração de europeus alfabetizados em virtude do surto do café contribui nas primeiras décadas do século XX na cidade de Birigui para a criação das escolas rurais de ensino primário. $E$ essa criação de escolas e oferta de vagas nos anos de 1940 se da em virtude da pauta de governo lembrando que segundo Camargo (2010)

[...] o valor da escola rural era traduzido como trabalho cívico, econômico e patriótico, capaz de restituir o sentido de brasilidade, que se cria ameaçado pelas ondas de imigração de raças inassimiláveis (alemães e japoneses, especialmente), e de combater o 'preconceito urbanista', fruto de nossa herança cosmopolita (p.104). 


\section{Considerações finais}

O processo de colonização e povoamento de Birigui foi marcado pela disputa da terra na qual o "poder" político econômico exercido na região durante as primeiras década do século XX ficou a cargo dos membros da Companhia de Terras, Madeiras e Colonização do Estado de São Paulo, tendo o monopólio do café, este, como já vimos, quebrado em virtude da queda da Bolsa de Nova Yorque.

Nesse sentido, vale lembrar que de acordo com Mendonça (2011) o ensino rural no Brasil foi fortemente marcado pela dualidade das relações sociais e de poder eregidas pelo capitalismo sofrendo a educação no século XX profundas alterações. Uma das apontadas pela referida autora se refere por vezes a iniciativas extremamente contemporâneas sobre a problemática, e, por vezes a alegada existência de um único modelo de ensino rural em todo o país, cuja origem está relacionada com a criação por Getulio Vargas, em 1931 do Ministério da Educação e Saúde.

Conclui-se diante de todo estudo realizado que a expansão do ensino primário rural birigüiense, criação de escolas e número de matrículas no período em foco vai ao encontro do que já apontou Ávila e Souza (2013). Num primeiro momento de combate ao analfabetismo e inserção da população aos novos conhecimentos produzidos pela modernidade mediante ao movimento de renovação educacional difundido no país pela Escola Nova e num segundo momento em virtude da política implantada pelo Estado Novo, sob o regime autoritário.

\section{Referências}

Ávila, V. P. S. (2013). História do ensino primário rural no estado de São Paulo e Santa Catarina (1921 - 1952): Uma abordagem comparada. Araraquara, 2013. Tese (Doutorado em Educação Escolar) - Faculdade de Ciências e Letras, Universidade Estadual Paulista, Araraquara.

Bigélli, I. F. S., \& Serra, Á. E. O percurso de uma alfabetizadora: formação e profissão. Revista ACOALFAplp, 5(9), 134-56. Recuperado de http://www.revistas.usp.br/reaa/article/view/11571.

Birigui. (1948). Birigui em sua $1^{a}$ concentração rural. Birigui: Gráfica Novos Rumos.

Camargo, A. P. R. (2010). Povoar o hinterland: o ensino rural como fronteira entre estatística e educação na trajetória de Teixeira de Freitas. Revista Brasileira de História da Educação, 23, 133-167.

Carramaschi, E. (1948). O problema do ensino primário na zona rural. In: BIRIGUI. Birigui em sua $1 \underline{a}$ concentração rural. Birigui, SP: Gráfica Novos Rumos. p.94-95.

Cerecedo, A. C., Los Rios, J. A. G., \& Fernández, C. E. (2011). Campesinos y escolares la construcción de la escuela em el campo latinoamericano: siglos XIX y XX. México: Miguel Angel Porrúa: El Colegio Mexiquense.

Elias, N. (1997). Os alemães: a luta pelo poder e a evolução do habitus nos séculos $X I X$ e XX. Rio de Janeiro: Jorge Zahar.

Ercilla, A. M., \& pinheiro, B. (Org.). (1928). O estado de São Paulo: zona noroeste. São Paulo: Propaganda Pan-americana. 
Freitas, S. M. (1999). E chegaram os imigrantes... (o café e a imigração em São Paulo) (2 $2^{\text {a }}$ ed.) São Paulo: edição da autora.

Lionetti, L., Civera, A., \& Werle, F. O. C. (2013). Sujetos, comunidades rurales y culturas escolares em América Latina. Rosario: Prohistoria Ediciones.

Mendonça, S. R (2011). Imperialismo, educácion rural y dualidad pedagógica em Brasil, 1946-1951. In A. C. Cerecedo.; J. A. G. Los Rios, \& C. E. Fernández, C. E. Campesinos y escolares la construcción de la escuela em el campo latinoamericano - siglos XIX y XX. México: Miguel Angel Porrúa; El Colegio Mexiquense.

Minicucci, V. (1948). $1^{\circ}$ Congresso rural de Birigui: escolas para a zona rural. In Birigui. Birigui em sua 1a concentração rural (69-72). Birigui: Gráfica Novos Rumos.

Moreira, A. C. (2008). História do café no Brasil. (1ª ed.) São Paulo: Magna Editora Cultural.

Os Municípios. (1939). A revista que o Brasil lê. São Paulo.

Pereira, M. A. F. Radiografia de la educación rural paulista (1936). In L. Lionetti, A. Civera, \& F. O. C. Werle. Sujetos, comunidades rurales y culturas escolares em América Latina. Rosario: Prohistoria Ediciones; El Colegio Mexiquense; El Colegio de Michoacán.

Pisani, S. (1937). Lo Stato di San Paolo nell Cinquantenario dell'Immgrarione. São Paulo.

Rémond, R. (Org.). (2003). Por uma história política (2ª ed.). Rio de Janeiro: FGV.

Serra, Á. E. (2007). A formação do professor alfabetizador em Birigui/SP (1961/1976). Araraquara: Junqueira \& Marin.

Serra, Á. E., \& Biancolin, R. A. (2011). Coleção Birigui Cem Anos (Fasc. 4). Araçatuba: Folha da Região.

Serra, Á. E. (2014a). A influência da imigração italiana nas escolas de Birigui - São Paulo - Brasil. In J. M. H. DÍAZ. Influencias italianas em la educación española e iberoamericana. Salamanca: Fahrenhouse.

Serra, Á. E. (2014b). La expansion de las escuelas primarias rurales de Birigui/SP en el contexto de la Segunda Guerra Mundial. Anais da International Standing Conference for The History of Education, Londres, Inglaterra, 36.

Souza, R. F., \& Ávila, V. P. S. (2013a). As disputas em torno do ensino primário rural (São Paulo, 1931-1947). (no prelo)

Souza, R. F., \& Ávila, V. P. S. (2013b). Para uma genealogia da escola primária rural: entre o espaço e a configuração pedagógica (São Paulo, 1889 - 1947). Anais do Congresso Brasileiro de História Ddaa Educação, Cuiabá, Brasil, 7.

\section{Notas}

\footnotetext{
${ }^{1}$ Também conhecida pela sigla NOB, a Estrada de Ferro Noroeste do Brasil com extensão de 1622 $\mathrm{km}$, partindo de Bauru até a divisa com a Bolívia, em Corumbá/ MS, fazendo a integração com a rede ferroviária boliviana até Sana Cruz de La Sierra, foi construída na primeira metade do século XX. Era uma ferrovia brasileira de bitola métrica. Passou a ser da iniciativa privada antes de ser completada em 1917 e, em 1957, foi incorporada a Rede Ferroviária Federal S.A., como uma de suas regionais. Quando desativada em 1996 (RFFSA), a ferrovia foi doada como Malha Oeste à Ferrovia Novoeste S.A. E, desde 2006, após a fusão da Novoeste S.A. e a Brasil Ferrovias, essa ferrovia passou a pertencer à América Latina Logística S.A.

${ }^{2}$ De acordo com Ercilla e Pinheiro (1928) e Soares (2003), a Companhia de Terras, Madeiras e Colonização de São Paulo foi fundada com os seguintes sócios: James Mellor (1.760 ações), diretor
} 
gerente; Roberto Clark (1.730 ações), ocupando o cargo de diretor técnico; Presciliano Pinto de Oliveira Clark (1.730 ações); Manoel Bento da Cruz (1.730 ações), diretor secretário; Edward Hamer (300 ações), ocupando o cargo de engenheiro e membro do conselho fiscal; Arlindo Lima (150 ações), ocupando o cargo de presidente; Francisco de Marchi (150 ações), José Bento Sampaio (150 ações); Franklin Keffer (150 ações), membro do conselho fiscal; e Augusto Elisio de C. Fonseca (150 ações), membro do conselho fiscal com o propósito de colonizar a vasta extensão de terras do Noroeste paulista registram a Ata de constituição da "The San Paulo Land, Lumber \& Colonization Company" no Segundo Tabelião de São Paulo, Capital em 16 de outubro de $1912 \mathrm{com}$ sede em São Paulo. Segundo alguns autores que escreveram sobre a empresa "The San Paulo Land, Lumber \& Colonization Company", o Coronel Manoel Bento da Cruz, este consegue amealhar 30 mil alqueires de terra acompanhando a Linha da CEFNOB por ter sido advogado de grileiros e antigos ocupantes na qual seus honorários eram pagos com terras, "e em alguns casos ficava com a maior extensão, bem como aquelas de localização privilegiada" (Martins, 1968, pp.68-69).

${ }^{3}$ Para evitar repetições desnecessárias, utilizarei a seguinte forma daqui em diante: (Companhia...).

${ }^{4}$ Estatística publicada na Revista Excelsior. Birigui, 1929.

5 De acordo com Ferreira (1980) a Revolução de 1930 foi um movimento organizado por elementos do Tenentismo, da classe média e da oligarquia rural, sendo os principais fatores políticos o Coronelismo, o Tenentismo e o sistema eleitoral. Um movimento político militar. Para maiores informações, ver: Ferreira, O. L.(1980). História do Brasil (3ª edição) São Paulo: Ática.

${ }^{6}$ Podemos localizar a escola tanto em seu ambiente local, nacional e global em uma relação de cumplicidade, a concorrência ou conflictividade com outras instituições culturais, sociais e econômicos, ou pensar a escola como processo: como resultado da ação de vários assuntos, bem como estrutura que marca os limites de sua ação em uma organização específica de tempo e espaço que é construído em suas rotinas diárias e rituais. (Tradução nossa).

${ }^{7}$ Decreto n. 5.884, de 21 de abril de 1933. Institui o Código de Educação do Estado de São Paulo. Secretaria da Educação e Saúde. São Paulo: Imprensa Oficial do Estado.

${ }^{8}$ São Paulo (1937). Annuario do ensino do estado de São Paulo: 1936-1937 (A Almeida Júnior, Org.). São Paulo: Typ. Siqueira, 1937.

${ }^{9}$ Esse período se divide em três fases: de 1930 a 1934, como chefe do Governo Provisório; de 1934 a 1937, comandou como Presidente da República do Governo Constitucional, tendo sido eleito pela Assembléia Nacional Constituinte de 1934; de 1937 a 1945, implantou o Estado Novo após o golpe de estado.

${ }^{10}$ Antonio Candido (1979) define bairro como "uma porção de território subordinado a uma povoação, onde se encontram grupos de casas afastadas do núcleo do povoado, e outras, em distâncias variáveis", grupos rurais de vizinhança.

${ }^{11}$ Este quadro foi elaborado a partir das informações coletadas em Mapa de Movimento das Escolas Municipais Rurais dos anos de 1931, 1945 e 1957, localizados na Diretoria de Ensino de Birigui.

${ }^{12}$ Foi consultado o Núcleo de Vida Escolar da Diretoria de Ensino de Birigui, responsável Teresa Rosa dos Reis, o Núcleo de Vida Escolar da Diretoria de Ensino de Araçatuba, responsável Marilisa Aparecida Tavelin Ora e o Núcleo de Vida Escolar da Diretoria de Ensino de Lins, responsável Rosane Lins de Castro Ablas, todas as respectivas responsáveis informaram que os acervos não possuem nenhum livro de matrícula referente às escolas rurais da região de Birigui no período compreendido entre 1920 e 1945. 